\title{
Derecho natural y derechos humanos: síntesis práctica y complementariedad teórica
}

\author{
Ana Marta González \\ Universidad de Navarra
}

The modern idea of human rights and the classical concept of natural law are not equivalent. Of course, they share the idea that not all law is conventional. But beyond this, the classical notion of natural law is clearly defined in the framework of the virtues, and consequently has a more practical orientation, and is more closely bound up with history; the notion of human rights, which has inherited the modern theories of natural rights, entails the subjectivization of the concept of right and tends to separate the human being from the historical and political context in which events take place. In this sense, the key concept associated with human rights is that of "dignity". Given that the two ideas have different starting points, and are different in their epistemological status, there are strictly speaking no grounds for devising a theoretical synthesis of the two theories. On the theoretical plane, we can only talk of their being complementary. The synthesis is something that will only come about in practice.

El lenguaje de los "derechos humanos" forma parte del bagaje ético de la cultura occidental contemporánea. En esas dos palabras han venido a concentrarse buena parte de nuestras intuiciones morales fundamentales; intuiciones relativas a las exigencias derivadas de la "dignidad de la persona", la otra expresión clave a la que acudimos espontáneamente cuando se trata de consignar el fundamento último de esos derechos: hay cosas debidas al hombre en razón de su peculiar dignidad. Y hay cosas (acciones) que contradicen dicha dignidad. 
En efecto: a pesar de que a lo largo de los siglos XIX y XX la idea de que el hombre es un ser particularmente digno ha sido atacada de múltiples maneras, es cierto también que, al menos en la opinión pública, la apelación a los derechos y a la dignidad humana se ha convertido en un lugar común cuando se abordan cuestiones éticas. Puede decirse, pues, quê al menos desde un punto de vista práctico la apelación a la dignidad y a los derechos está respaldada por un amplio consenso.

Sin embargo, hay importantes indicios para sospechar que semejante. consenso es sólo superficial. De hecho ya no nos sorprende el que apelando a los derechos humanos se pueda defender una postura y la contraria. En este contexto, la apelación a los derechos humános no parece ya sino un instrumento verbal .de cuya ambigüedad se alimenta a diario la retórica política de uno y otro signo; un instrumento formal al servicio de intereses partidistas. De este modo se cuestiona por su base la presunta universalidad de tales derechos, una de las intuiciones morales que este lenguaje venía a preservar:

¿Qué ocurre con los derechos humanos? ¿Por qué se prestan tan fácilmente a una instrumentalización semejante? Pero eso no es todo: ¿por qué la apelación a los derechos humanos se plantea a menudo en clave de conflicto (como ocurre en el:debate pro-life; pro-choice)? Preguntas como éstas; en particular- esta última, 'nos llevan a plantearnos cuestiones fundamentales $y$ cuestiones prácticas: cuestiones relativas al fundamento de la idea misma de derechos humanos; y cuestiones relativas'a su puesta en práctica.

'A este respecto, es sabido que'a lo largo de este siglo no han faltado intentos de poner en relación la doctrina clásica del derecho natural y la doctrina moderna de los derechos humanos. Entre ellos: se cuentan los de Maritain o Finnis ${ }^{1}$. Al mismo tiempo; no han faltado tampoco

${ }^{1}$ Cfr. Ernest L. ForTIN: "Medieval Origin of Individual Rights", en R. Hassing (ed:): Final Causality in Nature and Human Affairs, Washington, D. C.: Catholic 
autores que ven imposible una sintesis entre ambas ideas. En mi opinión, una sintesis teórica de ambas doctrinas es imposible, no sólo porque parten de premisas diferentes - de distintos conceptos del derecho-; sino porque ambas doctrinas gozan de un estatuto epistemológico diverso. A lo sumo podría hablarse de una sintesis práctica entre la doctrina clásica del derecho natural y los distintos Derechos Humanos, una síntesis orientada a la correcta aplicación de estos últimos. Precisamente a causa de las diferentes premisas y del diferente estatuto epistemológico, la palabra adecuada para designar la relación entre la doctrina clásica del derecho natural y la teoria moderna de los derechos humanos no sería tanto "síntesis" como complementariedad.

La tesis que acabo de enunciar se desglosa en varios puntos: 1) El lenguaje de los derechos humanos surge en Occidente en sintonía con la subjetivización de la idea de derecho iniciada a finalès de la Edad Media: En ello se advierte sin dificultad la diferencia existente entre las modernas declaraciones de derechos humanos, y la doctrina clásica del derecho natural, que era una doctrina eminentemente práctica, integrada en la virtud de la justicia 2) Una fundamentación consistente de los derechos humanos en la idea de dignidad debe remitir necesariamente, bien a un plano trascendental, bien a un plano ontológico. Por su parte, el esclarecimiento de la idea de dignidad permite profundizar en la naturależa misma de la justicia. 3) Cuando falta la remisión al plano trascendental, la idea de derechos humanos se confunde con el pensamiento liberal extremo, llevando a los conflictos antes apuntados. 4) Pero sin necesidad de llegar a las conclusiones del liberalismo extremo, la teoría moderna de los derechos humanos se distingue de la doctrina clásica del derecho natural tanto en su planteamiento teórico como en sus implicaciones

University of America Press 1997. Fortin menciona, además, a James Tully y, de otro modo, a Brian Tierney, quien, según explica Fortin, considera que hay claros precedentes de los derechos subjetivos modernos en la jurisprudencia del siglo XII y XIII. Cfr. ForTIN:"“Medieval Origin"..., p. 89. 
prácticas. Por esta razón no es posible una sintesis teórica. En cambio si cabe hablar de una síntesis práctica.

\section{Derecho natural y declaraciones de derechos humanos}

Como es bien sabido, las declaraciones de derechos humanos son un producto neto de la Ilustración ${ }^{2}$. Responden a una voluntad explícita de declarar una serie de verdades sobre las cuales habia acuerdo; en razón de qué, es otra cuestión. En general podemos admitir que dicho acuerdo se basa en la convicción de que el hombre es un ser dotado de una particular dignidad, dignidad que le hace titular de unos derechos inalienables.

En todo caso, ese acto -declarar-se asociaba entonces y hoy a la palabra escrita. Siendo como es un acto político de la mayor relevancia, el hecho de querer una declaración escrita de los derechos humanos esconde, no obstante, cierta desconfianza ante la palabra oral ${ }^{3}$; desconfianza también ante el sentido interior de justicia que preside naturalmente las relaciones entre seres humanos civilizados.

Merece la pena indicar que en este punto. las declaraciones de derechos humanos se distinguen claramente del derecho natural clásico. Éste se caracterizaba; precisamente, por ser un derecho no escrito, o, como ha expresado Spaemann en alguna ocasión, "más una mentalidad que un código de normas"4. Es decir, algo vivo: el derecho nacido de aquella "ley no escrita"s a la que habia apelado Antigona en

2 Cfr. A. Ferrary: "De los 'Derechos del Hombre' a la Declaración de los Derechos Humanos': un recorrido por la historia". Inédito.

3 Un espiritu totalmente diverso del que animaba a Platón cuando escribió el conocido mito de Theuth, acerca del origen de la escritura. La fe de la Ilustración en la palabra escrita sería para Platón una ilusión, pero además una ilusión ingenua. Cfr. Platón: Fedro, 274 e- 275 e6.

4 Cfr. R. SpaEmanN: "La actualidad del derecho natural" en Critica de las Utopias Políticas, Pamplona: Eunsa 1980.

5 Cfr. J. MARITAIN: La loi naturelle ou loi non écrite, texte inédit, établi par Georges Brazzola, Fribourg (Suisse): Editions Universitaires 1986. 
su enfrentamiento con Creonte; una ley que, por esto mismo, se ha llamado tradicionalmente "ley natural", una de las pocas nociones, dicho sea de paso, cuya problematicidad es comparable a la de los "derechos humanos".

Aunque éste no es el lugar apropiado para entrar en el tema de la ley natural, se hace necesario decir una palabra al respecto, por cuanto los dos asuntos se encuentran relacionados. Como es sábido, aunque existen precedentes en algún fragmento de Heráclito, la apelación a la "ley natural" como criterio moral se atribuye ordinariamente al estoicismo. Para ellos seguir la ley natural equivalia a representar el papel que cada uno tenía asignado en el gran drama del Universo; en el caso del hombre, esto equivalia a secundar la razón natural, lo cual, para los estoicos, implicaba el cultivo de la apatía. De esta manera, el estoicismo separaba razón y pasión, unidas en la ética aristotélica.

Efectivamente, vivir según la razón tenia, para Aristóteles, otro sentido. Equivalía a vivir según la virtud. Pero, a diferencia de la estoica, la virtud aristotélica no excluía la presencia de la pasión. Al contrario. El hombre bueno de Aristóteles no era un apático: Lo que le distinguía era haber alcanzado el tẹrmino medio. Hallar y prescribir el término medio caracteristico de cualquier virtud era la tarea específica de la prudencia, una virtud intelectual que, según Aristóteles, no existe sin la virtud moral. La virtud es el concepto clave de la ética aristotélica. Propiamente, Aristóteles no habló nunca de "ley natural". Como acabo de indicar, hablaba más bien, de "vivir según la razón", lo cual, para él era equivalente a "vivir según la virtud". Reparar en esto es conveniente, porque cuando Tomás de Aquino exponga su ley natural, tendrá particularmente presente la ética aristotélica de la virtud en mayor medida incluso que la ley natural estoica, algo que no conviene perder de vista, si consideramos que, al decir de Tuck ${ }^{6}$, Tomás de Aquino constituye un punto de

6 Cfr. R. Tuck: Natural Rights Theories: Their origin and their development, Cambridge University Press 1979, p. 18. 
inflexión en la historia del derecho natural. Concretamente conviene no perder dé vista que Tomás de Aquino,' como Aristóteles, nó desvincula el tratamiento del derechó natural de la virtud de la justicia. El asunto tiene su importancia.

En efecto, como toda virtud, también la justicia consiste en un cierto término medio. Sin embargo, el término medio en el que consiste la justicia tiene una caracteristica particular: no es un término medio relativo al agente -como sería el caso en la templanza o la valentía-, sino un término medio relativo a la cosá, de tal modo que puede determinarse con independencia de las disposiciones del agente. De: esta manera, en èl caso concreto dè la justicia puede establecerse una distinción más nítida entre "hacer lo justo" y. "ser justo". Con todo, para poseer la virtud de la justicia no es suficiente con "hacer lo justo", sino que es preciso hacerlo como lo hace el hombre justo, es decir: con una voluntad deliberada de dar a cada uno lo suyo.

Estas consideraciones no constituyen un simple excursus. Ya he señalado que Aristóteles no habla, propiamente, de "ley natural": Sin embargo sí habla de justicia natural, y en unos términos sobre los que conviene reparar: El liugar exacto donde se refiere a la justicia natural es en el capitulo séptimo del conocido libro V de la Ética a Nicómaco. Alli comienza diciendo: "la justicia política se divide en natural y legal". A un lector moderno le sorprenderá, seguramente, esta inclusión inicial de la justicia natural dentro de la justicia política, porque, más familiarizado con las teorías' modernas de "derechos naturales", tenderá a pensar en el derecho natural como' en unas prerrogativas anteriores a la constitución de la comunidad política, como se da, paradigmáticamente, en el planteamiento de Locke. Así, mientras que Aristóteles dividia la justicia política en natural y legal, mostrando, entre tanto, que para él no existe un derecho prepolítico - el mismo derecho natural sería parte del derecho político-, John Locke hablará de "derechos naturales" en un preciso sentido prepolítico: antes del pacto social, los individuos poseen derechos inalienables. 
Ahora bien: la postura de Aristóteles puede comprenderse si consideramos que él se acerca al Derecho desde un punto de vista dinámico, es decir, desde el punto de vista del agente, en el contexto de una teoría de las virtudes. Desde este planteamiento, en efecto, la justicia que habia de vivir el ciudadano abarcaba dos aspectos: la justicia legal y la justicia natural ${ }^{7}$. En su planteamiento, la competencia especifica de la justicia natural era, precisamente, cubrir el vacío dejado por la justicia legal. Ahora bien, ser justo cuando no hay pautas positivas, o cuando las pautas se han quedado obsoletas, es un asunto que invita a actualizar el hábito moral de justicia.

A diferencia de Aristóteles, que se sitúa en un punto de vista estrictamente ético, Locke elabora una teoria política, con la que procura defender al individuo de los excesos del poder político. $\mathrm{Y}$, con este fin, las hipótesis del estado de naturaleza y de unos derechos prepolíticos tienen una utilidad evidente. En la medida en que esta manera de hablar tiene la ventaja de subrayar la trascendencia del hombre respecto de cualquier sistema político, es posible que en algún caso nuestra situación siga requiriendo un lenguaje parecido ${ }^{8}$. Sin embargo, no conviene olvidar que se trata de un modelo teórico que, al tiempo que destaca un aspecto, oscurece otros posiblemente tan importantes. Concretamente oscurece uno que en la doctrina clásica del derecho natural se admitía sin problemas: la historicidad del derecho natural.

Cuando en este contexto se habla de "historicidad del derecho natural" no se enuncia ninguna tesis historicista. No se dice que cambie la naturaleza de la justicia. Se dice simplemente que cambian las circunstancias en las que se debe vivir la justicia. Con otras palabras: el hábito moral por el que nuestra voluntad quiere dar a cada uno lo suyo es siempre el mismo. Pero pueden cambiar las

${ }^{7}$ Cfr. ARIstóteles: Ética a Nicómaco, V, 7. Cfr. SANTO TOMÁs DE AQUINO: In V Ethic., lectio XII.

${ }^{8}$ En ello precisamente se apoya el planteamiento de Rawls: Political Liberalism, New York: Columbia University Press 1993. 
circunstancias que concurren a la definición de "lo suyo". En este sentido, la formulación escrita del derecho natural tiene siempre algo de problemático. Sin duda es necesaria en algunos casos, pero, si no se quiere. llegar a una conclusión historicista, importa mucho advertir que la formulación positiva del derecho natural no es el derecho natural in actu exercitu.

De todos modos, la inclusión de la justicia natural en la justicia política, no es la única diferencia entre el derecho natural clásico ${ }^{9}$ y el moderno. Otra diferencia, no menos importante, es la transformación del concepto mismo de ius, de derecho. En el planteamiento aristotélico, lo justo no surge por referencia a una naturaleza pura, sino en el contexto de la convivencia social, que es el lugar natural de la justicia. Para Aristóteles, en efecto, el hombre es un ser naturalmente social.

Ahora bien, ¿qué significa que el hombre sea social por naturaleza? Por lo pronto dos cosas: de un lado, que es naturalmente apto para la vida social (si bien deberá actualizar libremente dicha aptitud). De otro, que sólo en sociedad llega a manifestarse plenamente como humano, pues sólo en sociedad recibe el lenguaje y la educación necesaria para ello. Sin duda sólo llegará a manifestarse como humano porque previamente es humano. Pero, al mismo tiempo, 'a posibilidad de manifestarse como humano viene por la $\operatorname{sociedad~}^{10} \mathrm{y}$,

9 En su Comentario a la Ética a Nicómaco, Tomás de Aquino advierte de las diferencias entre el planteamiento aristotélico y el de los juristas romanos, quienes distinguian simplemente entre justicia natural y justicia legal. Sin embargo, Tomás de Aquino logra una explicación conciliadora: mientras que los juristas romanos realizan su división del derecho atendiendo a la causa (es decir, atendiendo a si la causa es la naturaleza o la convención), Aristóteles realiza su división atendiendo al uso. Y efectivamente: desde el punto de vista del uso, tanto el derecho natural como el derecho legal son usados por el ciudadano, y se incluyèn, por eso, en la justicia política. Cfr. TOMÁs dE Aquino: In V Ethic. Nic., lectio 12. Cfr. A. M. GonZÁlez: Moral, Razón y Naturaleza, Pamplona: EUNSA 1998, p. 299 ss.

$10 \mathrm{Cfr}$. Charles TAYLOR: La ética de la autenticidad, Barcelona-Buenos AiresMéxico: Paidós 1994. 
en este sentido, todo hombre nace en deuda con la sociedad. Ciertamente no estamos en deuda con la sociedad por lo que hace a nuestra condición esencial de hombres. Pero sí por lo que hace a la realización práctica de nuestra vida ${ }^{11}$. Ahora bien: a esta realización práctica pertenece la convivencia con otros seres humanos. $\mathrm{Y}$ es en esta convivencia, entre seres semejantes, dotados todos de palabra, y no simplemente de $v^{12} z^{12}$, donde nacen naturalmente, las relaciones de justicia, dentro de las cuales se descubre el sentido genuino del ius, del derecho: no tanto una "posesión", cuanto una "relación"; concretamente una relación de tres términos: "A debe $\mathrm{B}$ a C", que, como ha indicado Finnis, es convertible con esta otra: " $\mathrm{C}$ tiene derecho a B de A"13.

Pues bien: es precisamente esta visión del derecho como relación de tres términos lo que se pierde de vista en el lenguaje de los derechos humanos, donde el hombre aparece como un sujeto poseedor, y poseedor absoluto, de un derecho, no ya frente a un tercera persona, sino indeterminadamente y frente al mundo en general ${ }^{14}$. Por el

\footnotetext{
${ }^{11}$ Cfr. Platón: Critón.

12 Cfr. ARISTóteles: Politica, I.

${ }^{13}$ Cfr. Natural Law and Natural Rights, Oxford: New York University Press 1980, pp. 201-202. Cfr. C. MAssins: "Realismo y Derechos Humanos", en Atlántida, $1 / 1990$, p. 56.
}

14 Éste es el prisma peculiar bajo el que el hombre contemporáneo filtra la experiencia moral: la percepción de lo que se me debe en general en razón de mi dignidad, casi sin importar quién me lo deba, y casi sin advertir si yo, a mi vez, debo algo a alguien. No es que no se tenga percepción de estos dos aspectos. Sin embargo, culturalmente se favorece la otra perspectiva. De ahi los extraordinarios esfuerzos teóricos dirigidos a equilibrar la particular percepción de la experiencia moral proporcionada por el lenguaje de los derechos humanos, y la insistencia casi tediosa en la necesidad de subrayar, al mismo tiempo, los deberes. Casi de manera instintiva asociamos dignidad y derechos: en razón de su peculiar dignidad, decimos, el hombre es "sujeto de derechos". El riesgo implícito en esta forma de hablar estriba en olvidar que la dignidad es -por utilizar la terminología modernatambién fuente de deberes. Se trata de un riesgo derivado de las connotaciones que con el tiempo han ido adquiriendo las palabras que usamos. A lo largo de la historia, en efecto, hemos llegado a concebir los derechos en términos de demandas o exigencias absolutas, de tal manera que, a la hora de afrontar la relación entre 
contrario, en el pensamiento de Aristóteles, y también en el de los juristas romanos, el ius no era primariamente una posesión sino una relación. Ahora bien, como ha mostrado Tuck ${ }^{15}$, a lo largo de la Edad Media la idea de ius se fue asimilando a la de dominium, y, consecuentemente, el derecho pasó a interpretarse más en términos de posesión que en términos de relación. Interpretando el derecho en estos términos ${ }^{16}$, se perdía el sentido objetivo que tenía en el derecho natural clásico, y se favorecía una interpretación subjetiva del derecho. Esta interpretación es la que está en la base de la exposición que hace Hobbes del derecho natural ${ }^{17}$, y, por supuesto, en la teoría lockeana de los derechos naturales.

En sintonía con la argumentación desarrollada por König en su libro sobre la fundamentación de los derechos humanos ${ }^{18}$, podemos ver en estos "derechos naturales" el precedente más inmediato de los modernos derechos humanos. En su discurso, König advierte una continuidad entre el planteamiento de Hobbes y el de Locke ${ }^{19}$, y advierte en las deficiencias de este último, concretamente en su fundamentación individualista (que forzará dos siglos después la insistencia marxista en los derechos colectivos) la ocasión para un

dignidad y derechos, terminamos considerando al hombre casi exclusivamente como sujeto pasivo de la acción de otros, olvidando que la dignidad, en cuanto tal, se expresa sobre todo con las propias acciones.

15 Cfr. R. TUCK: Natural Rights Theories. Their origin and development..., p. 20

16 Cfr. F. INCIARTE: "Natur- und/oder Vernunftrecht. 30 Thesen und ein Versuch", en Menschenrechte und Entwicklung. Im Dialog mit Lateinamerika, F. Inciarte, \& B. Wald (eds.), Münster: Vervuert Verlag 1992, pp. 87-99.

17 'El derecho natural, que los escritores llaman comúnmente 'ius naturale', es la libertad que tiene cada hombre de usar su propio poder según le plazca, para la preservación de su propia naturaleza, esto es, de su propia vida; $y$, consecuentemente, de hacer cualquier cosa que, conforme a su juicio y razón, se conciba como la más apta para alcanzar ese fin": Thomas HoBBes: Leviatán, Madrid: Alianza Universitaria 1996, p. 110.

18 Cfr. S. König: Zur Begrïndung der Menschenrechte: Hobbes, Locke, Kant, Freiburg-München: Alber Reihe Praktische Philosophie 1994.

${ }^{19}$ Continuidad señalada también por FoRTIN: "Medieval Origin"..., p. 95. 
planteamiento trascendental como el kantiano, en el que dicha dialéctica se supera. Aunque el planteamiento de Kant no está exento de problemas, constituye, a juicio de König, el intento más acabado de otorgar una fundamentación a los derechos humanos, dentro de las limitaciones impuestas por el propio método trascendental.

En efecto, además de superar la disyuntiva de un modo que permite equilibrar su tensión entre derechos individuales y colectivos, el sistema kantiano permite resolver un problema frecuente en los planteamientos contemporáneos: el conflicto de derechos. Este problema surge siempre que se habla de derechos en plural y se entiende cada uno de ellos como absoluto ${ }^{20}$. A Kant no se le plantea el conflicto porque, a diferencia de Locke, habla de un único derecho humano, que no es otro que el derecho a la libertad, al que otorga un estatuto trascendental. La aparente sobriedad de este planteamiento se subsana tan pronto como advertimos que, para Kant, este único derecho trascendental encuentra expresión inmudiata en ciertos derechos fundamentales -derecho a la libertad personal, a la igualdad ante la ley, y a la libertad de pensamiento ${ }^{21}$ - que a su vez se deberán ir concretando de diversos modos a lo largo de la historia.

Todo lo dicho hasta el momento puede resumirse como sigue: la idea de derechos humanos es típicamente moderna. Responde a la subjetivización de la idea de Derecho ya consumada en las modernas teorías de derechos naturales, si bien, la expresión "derechos humanos" se encuentra en Kant por vez primera. Y es Kant,

${ }^{20}$ Dicho conflicto estaba fuera de lugar en la teoria clásica del derecho natural, aunque por un motivo distinto al de Kant. Clásicamente, en efecto, no se hablaba de un único derecho trascendental. Sin embargo, se hablaba de la unidad moral de las virtudes $y$, como ya hemos apuntado, se entendia el derecho en conexión con éstas, lo cual excluia la idea de un conflicto de derechos. Pues según Aristóteles, las virtudes morales -incluida, naturalmente, la justicia- no pueden existir sin prudencia: ese saber práctico cuya naturaleza consiste, precisamente, en "saber usar» los hábitos; un saber que, en cualquier caso, no es codificable, y que no se da, a su vez, sin virtud moral.

${ }^{21}$ Cfr. S. KônIG: Zur Begriundung der Menschenrechte..., p. 272. 
igualmente, el punto de referencia al que debemos acudir en busca de su fundamentación. Esto no quiere decir, naturalmente, que la idea de derechos humanos no admita otro tipo de fundamentación. Aunque el pensamiento clásico no se aplicó expresamente a esta tarea, en él se encuentran los elementos necesarios para elaborar una fundamentación que no tiene nada que envidiar a la kantiana y que, hablando en términos absolutos, resulta todavía mucho más consistente. Sea como fuere, es cierto que dicha fundamentación requiere salirse del plano práctico en el que se mueve el derecho natural clásico, y hacer explícitas una serie de premisas ontológicas relativas a la idea misma de dignidad.

2. La fundamentación de los derechos humanos. Dignidad ontológica/dignidad trascendental.

¿Qué hemos de entender por dignidad? Como es sabido, la palabra dignitas es la traducción latina para el término axioma, de origen griego $^{22}$. Ahora bien: un axioma es algo que no se cuestiona a lo largo de un discurso, y como la piedra de toque de todo discurso. En este sentido, al hablar de dignidad humana mentamos lo que, tratándose del ser humano, no puede ponerse en cuestión porque constituye el principio de todo lo genuinamente humano.

Hasta cierto punto, lo que decimos del hombre, de la dignidad humana, cabría extenderlo al resto de los seres vivos. Hablariamos asi de la dignidad de un viejo roble, o de un león, queriendo apuntar con ello a lo que constituye al roble en roble, o al león en león ${ }^{23}$. Sin embargo, al hablar de dignidad humana, apuntamos también algo distinto. La dignidad humana es una dignidad peculiar, hemos dicho.

22 Cfr. TomÁs DE Aquino: Summa Theologiae, I- $\Pi^{\text {ae }}$, q. 94, a. 2, citado por R. SimON: "Le concept de dignité de l'homme en ethique", en De Dignitate hominis, ed. A. Holderegger, R. Imbach, R. Suárez de Miguel, Freibourg-Schweiz: Universitätsverlag 1987, pp. 263-278, p. 265.

23 Cfr. R. SPaEmanN: "Acerca del concepto de dignidad humana", en Lo natural y" lo racional, Madrid: Rialp 1990. 
No sólo porque el hombre puede no estar a la altura de su propia dignidad en un grado mayor que los demás seres; en rigor, esta posibilidad -que da razón de la mayor o menor dignidad moral de una persona- se sigue de lo que, en un plano más radical, constituye al hombre, a cada hombre, en un ser particularmente digno: su personal originalidad, su dignidad -vamos a llamarla así- trascendental u ontológica ${ }^{24}$. En efecto: cada ser humano comparte con otros muchos su pertenencia a la especie humana, y en este sentido podría decirse de él que es un miembro de la especie, de modo análogo a como un perro lo es de la especie perro. Sin embargo, esto no es así. Cada individuo humano es mucho más que un miembro de una clase ${ }^{25}$. Lo que un hombre es -más allá de lo que un hombre hace- no queda definido del todo al constatar su pertenencia a la especie homo. Cada ser humano real, cada ser humano concreto, realiza esa especie de un modo único. Esta unicidad, esta originalidad, no se refiere únicamente a sus eventuales peculiaridades biológicas, psíquicas o incluso culturales; no se refiere a diferencias de tipo cualitativo, sino a una diferencia que, adoptando la terminología kantiana, podemos llamar trascendental.

Si le preguntáramos a Kant qué es lo que hace a un hombre radicalmente distinto de otro respondería sin vacilar que la libertad. Con ello Kant no se está refiriendo a la mera libertad de elección, a una libertad medial. Kant estaba pensando en algo más profundo, a saber: que, a diferencia de lo que ocurre en los demás seres naturales, que se comportan de acuerdo con los fines que les vienen impuestos por la naturaleza, el hombre puede ponerse fines a sí mismo. $\mathrm{Su}$ libertad no se limita a ser una libertad medial, sino una libertad trascendental. En ello radica, para Kant, la originalidad de la persona

24 Acerca de la distinción entre dignidad trascendental y moral, cfr. A. M GonzÁleZ: Naturaleza y Dignidad. Un estudio desde Robert Spaemann, Pamplona: EUNSA 1996, capítulo 2:

25 Cfr. R. SPaEmann: Personen. Versuche über den Unterschied zwischen, etwas' und jemand', Stuttgart: Klett-Cotta 1996, capítulo 1. 
humana ${ }^{26}$. A ello se refiere cuando afirma que el hombre es fin en sí mismo, haciendo consistir en ello su dignidad peculiar ${ }^{27}$. Aquí tenemos el origen de la "antropología en sentido trascendental", que Kant distingue expresamente de la "antropología en sentido pragmático": mientras que esta última habla de lo que la naturaleza hace del hombre, aquella hablaría de lo que el hombre hace a partir de sí mismo, a partir de su libertad ${ }^{28}$.

En esta observación de Kant hay, indudablemente, mucho de verdadero. Ciertamente, los "riesgos" también están a la vista. En particular, esa misma contraposición tajante entre naturaleza y libertad, que resulta tan iluminadora desde muchos otros puntos de vista, se convierte en problemática tan pronto nos salimos del sistema trascendental kantiano. Fuera del sistema trascendental, en efecto, la precedencia absoluta de la libertad es una invitación a revivir el dualismo cartesiano entre res extensa y res cogitans, que esta vez. adopta la forma de una insuperable dialéctica entre naturaleza y libertad. En este contexto, el hombre termina por identificarse con la

26 Cfr. I. KANT: Grundlegung zur Metaphysik der Sitten, Ak. IV, p. 437, 21-23.

27 Cfr. I. KANT: Grundlegung zur Metaphysik der Sitten, Ak. IV, p. 436, 6-7.

28 "Eine Lehre von der Kenntmis des Menschen, sistematisch abgefaßt (Anthropologie), kann es etweder in phisiologischer oder in pragmatischer Hinsicht sein.- Die phisiologische Menschenkenntmis geht auf die Erfooschung dessen, was er als freihandelndes Wessen aus sich selber macht, oder machen kann und soll.- Wer den Naturursachen nachgrïbelt, worauf, z. B. das Erinnerungsvermögen beruhen möge, kann ïber die im Gehim zurückbleibenden Spuren von Eindrïcken, welche die erlittenen Empfindungen hinterlassen, hin und her (nach dem Cartesius) vemünfteln; muß aber dabei gestehen: daß er in diesem Spiel siner Vorstellungen bloßser Zuschauer sei und die Natur machen lassen muß, indem er die Gehimnerven und Fasem nicht kennt, noch sich auf die Handhabung derselben zu seiner Absicht versteht, mithin alles theoretische Verniinfteln hierïber reiner Verlußt ist.- Wenn er aber die Wahmehmungen über das, was dem Gedächtnis hinderlich oder beförderlich befunden worden, dazu benutzt, um es zu erweitern oder gewandt zu machen, und hiezu die Kenntnis des Menschen braucht, so würde dieses einen Theil der Anthropologie in pragmatischer Absicht ausmachen, und das ist eben die, mit welcher wir uns hier beschaffigen': I. KANT: "Anthopologie in pragmatischer Hinsicht", en Kant's Werke, Band VII, Berlin, 1917 , p. 120. 
libertad, y la naturaleza pasa a considerarse solamente el material del que el hombre dispone para realizar sus proyectos.

Una fundamentación de la idea de derechos humanos diversa de la kantiana y que no conduzca a la dialéctica mencionada sólo es posible alli donde no haya tenido lugar el giro inmanentista ${ }^{29}$, que al encerrar al hombre en su conciencia, le obliga a pensar la diferencia entre lo ideal y lo real univocamente, en términos de facticidad pura ${ }^{30}$. Sobre este supuesto gnoseológico, en efecto, la naturaleza -tanto la humana como la no humana- es siempre lo ajeno a la conciencia. Y en la medida en que el hombre se identifica más con la conciencia, se aleja más y más de la naturaleza. Sobre un supuesto inmanentista, en fin, no hay ya lugar para el pensamiento analógico que permite reconocer la peculiaridad de una naturaleza racional. Con estas premisas no resulta fácil mostrar en qué medida el respeto al hombre y a su dignidad va unido al respeto a su naturaleza, de tal manera que el concepto mismo de dignidad termina siendo una palabra vacia ${ }^{31}$, que puede rellenarse con un contenido arbitrario. Si el planteamiento de Kant, a pesar de su inmanentismo, evitaba esta conclusión, la razón debe buscarse en el método, en el método trascendental, que, como ha mostrado Prauss ${ }^{32}$, acaso comporte una previa naturalización de la razón.

Más allá de la fundamentacion trascendental, la única fundamentación posible para la idea de dignidad y derechos humanos supone trascender el principio inmanentista y afirmar simple y llanamente que esta dignidad y estos derechos se fundamentan en el

${ }^{29}$ Cfr. J. MARECHAL: El punto de partida de la metafisica, Madrid: Gredos 1957. Cfr. A. Llano: Fenómeno y Trascendencia en Kant, Pamplona: Eunsa 1973.

${ }^{30}$ Cfr. L. Polo: Evidencia y Realidad en Descartes, Pamplona: EUNSA, $2^{\mathrm{a}}$ ed. 1996

31 Cfr. T. Melendo \& L. Millán: Dignidad: ¿una palabra vacia?, Pamplona: EUNSA 1996.

32 Cfr. G. PRAUSs: Kant: itber Freiheit als Autonomie, Frankfurt am Main: Vittorio Klostermann 1983. 
mismo ser humano, de tal manera que el mismo ser humano ${ }^{33}$ constituye ya un título por el que un individuo puede reclamar ser tratado de una manera concreta: por lo pronto como lo pide su naturaleza especifica. El criterio más universal del que disponemos para distinguir las acciones que ayudan y las acciones que dañan al ser humano, elemental, pero no por ello menos cierto, nos lo proporciona la naturaleza con sus inclinaciones específicas ${ }^{34}$.

Ahora bien, afirmar que el criterio de ayuda y daño es natural, es distinto de afirmar que el fundamento de la dignidad es natural. Esto no es cierto. El fundamento en cuestión - lo hemos apuntado ya- no es cualitativo sino -por usar la terminologia kantiana- trascendental: ontológico, si preferimos la terminología clásica. Con estas últimas palabras indicamos que no es merced a propiedad alguna por lo que el hombre es digno, sino simplemente por ser, por existir como un individuo humano. Dicho de otro modo: la naturaleza humana, considerada en abstracto, no es digna. Dignos son los hombres concretos, los hombres existentes. Si preguntáramos a Tomás de Aquino por qué son dignos los hombres nos responderia: porque el ser racional es querido por sí mismo ${ }^{35}$ : Dios lo quiere por sí mismo. Desde este planteamiento, la raiz de la dignidad humana estriba en ser imagen de $\operatorname{Dios}^{36}$, en haber sido objeto de un acto explicito de amor

33 Naturalmente, se pueden plantear problemas a la hora de precisar quiénes son esos humanos (cfr. A. CRUz PraDos: "Derechos Humanos: ¿Qué derechos? ¿De qué humanos?", en Nuestro Tiempo, $n^{\circ}$ 525, marzo 1998, pp. 102-115). A este respecto, parece oportuno señalar que la idea misma de dignidad humana, por la cual todo hombre se hace sujeto de derechos, sólo tiene sentido si el criterio de humanidad es natural, y no fruto de una convención o artificio humano, pues con ello unos hombres decidirian sobre la dignidad de otros.

34 Cfr. A. M. GONZÁlez: Moral, Razón y Naturaleza. Una investigación sobre Tomás de Aquino, Pamplona: Eunsa 1998, capitulo 2.

35 "Quae igitur semper sunt in entibus, sumt propter se a Deo volita: quae non autem semper, non propter se, sed propter aliud. Substantiae autem intellectuales maxime accedunt ad hoc quod sint semper, quia sunt incornuptibiles (...) ergo substantiae intellectuales gubematur quasi propter se, alia vero propter ipsas". Cfr. Contra Gentes, II c. 112, n. 2862.

${ }^{36}$ Cfr. A. M. González: Moral, Razón y Naturaleza..., pp. 33-37. 
por parte de Dios. De acuerdo con ello, el hombre manifiesta máximamente su dignidad cuando acepta y secunda libremente la racionalidad incoada en su naturaleza, siempre y cuando no entienda esta fórmula a la manera estoica -como sujeción a una fuerza impersonal, o sea, el destino-, es decir, siempre y cuando acierte a reconocer la inteligencia y la voluntad de un ser personal detrás de esa racionalidad natural ${ }^{37}$.

A pesar de la semejanza existente entre esta afirmación de Tomás de Aquino -el ser racional es querido por sí mismo- con la formulación kantiana que hace consistir la peculiar dignidad del hombre en su carácter de fin en sí mismo, las dos formulaciones delatan al mismo tiempo los diferentes universos conceptuales en los que se mueven los dos pensadores. De entrada, esos dos universos conceptuales, tan alejados entre sí como lo pueden estar el idealismo y el realismo filosófico, no comportan especiales diferencias en la práctica. Así, por ejemplo, la insistencia kantiana en que la humanidad no debe ser tratada -en uno mismo o en otro- sólo como medio, porque es fin en sí misma, no puede sino despertar la simpatía de los que reconocen la dignidad de la persona humana, por mucho que justifiquen esta centralidad de manera diferente.

No obstante, lo que me importa destacar aquí es que la apelación a la dignidad de la persona, como el fundamento de los derechos humanos - ya se haga en términos kantianos, ya se presente como una reelaboración de elementos presentes en el pensamiento de Tomás de Aquino- se mueve en un plano diverso del derecho natural clásico. Pues mientras que el derecho natural clásico era un asunto eminentemente práctico, la teoría de los derechos humanos pone en juego explícitamente premisas metafisicas que, no obstante, pueden y deben contribuir a una mayor profundización en la naturaleza de la justicia.

37 Es decir, siempre que actúe según la ratio superior, y no según la ratio inferior. Cfr. Tomás de AQuino, De Veritate, q. 15. 
3. Profundizar en la idea de justicia, a la luz de la idea de dignidad

En efecto: de acuerdo con lo anterior, afirmar que todos los hombres son iguales en un plano ontológico-trascendental no puede entenderse en un sentido tal que suprima las relaciones prácticas de justicia connaturales a la vida social. Cabe decirlo de otra manera: la igual dignidad trascendental $u$ ontológica no anula la mayor o menor dignidad moral. Precisamente es la misma igualdad trascendental la que reclama dignidad moral, y la que muestra, en su caso, la diferente dignidad moral de los hombres. Con todo, es cierto que una mayor conciencia de la dignidad trascendental, permite calibrar mejor la igualdad radical entre los hombres, justificando asi una mayor profundización en la naturaleza de la justicia.

Indicaciones importantes sobre el particular se encontraban ya en el pensamiento clásico. Pienso sobre todo en la frase más comentada del Gorgias de Platón: "más vale padecer la injusticia que cometerla". Lo que con ello se nos dice, en efecto, es que el comete injusticia queda en una posición más desgraciada que el que la padece: ciertamente no en términos de "bienes y males" externos, sino en términos de bien y mal humanos, es decir, en términos de dignidad moral. En términos de dignidad, en efecto, el que más pierde con la injusticia no es el que la sufre sino el que la comete: él es el primero que no actúa como cabe esperar de un hombre: él es el primero que no actúa justamente. Ahí se puede detectar una desigualdad más profunda que la mera desigualdad externa, una desigualdad profunda que acaso la justicia humana no puede nunca llegar a restablecer del todo, porque afecta al núcleo de la persona, a su voluntad.

Inspirados por esta visión profunda de la dignidad humana, es posible profundizar más en la naturaleza de la justicia. Consistiendo la justicia siempre en una "cierta igualdad", cabe decir ahora que la reparación de una injusticia ha de mirar mucho más lejos, por ejemplo, que la restitución material de los bienes robados, pues tiene que atender también a la restauración de la buena voluntad del 
infractor. De este pensamiento cabe extraer una consecuencia práctica acerca de la justicia de los castigos. El castigo pertenece a la restauración de la justicia. Pero un castigo justo ha de aspirar, además, a la rectificación de la voluntad del infractor.

Si consideramos la historia del pensamiento europeo, podemos detectar seguramente algunos avances en este sentido. Fundamentalmente por influencia del cristianismo, la ley del talión -que responde a un balance material de bienes y males- ha desaparecido de Occidente. Hemos pasado a una comprensión más profunda de la justicia, donde no cuenta tanto la materia como la forma ${ }^{38}$. Sin embargo, para que no se pierda el genuino sentido de este progreso es importante advertir que, desde esta perspectiva, la justicia de un castigo supone incorporar un elemento de corrección: un castigo justo debe ayudar a restablecer la buena voluntad ${ }^{39}$.

\section{Excursus: la postura del liberalismo extremo}

La posibilidad de un castigo justo es una idea poco en sintonía con la postura de lo que podríamos llamar "liberalismo extremo", una posición en la que la apelación a la "dignidad" humana ha llegado a constituirse en un arma de doble filo, precisamente porque, acogiendo la idea de dignidad como autonomia absoluta, prescinde tanto de la fundamentanción trascendental kantiana como de la fundamentación ontológica clásica. En sintonía con este planteamiento de la dignidad, los derechos humanos pasan a ser interpretados única $y$ exclusivamente como puros derechos subjetivos, ordenados a posibilitar la puesta en práctica del proyecto de vida que uno ha elegido para $\mathrm{si}^{40}$. Con ello se consuma la subjetivización de la idea de

38 Cfr. J. Finnis: Natural Law. Natural Rights, Oxford Clarendon Press, 1980.

39 Con ello no se excluye por principio la justicia de la pena de muerte. Puede haber casos en los que semejante castigo -0 , más bien, la perspectiva de un castigo semejante- sea lo único que haga reaccionar a una voluntad endurecida.

40 Para lo cual ni siquiera sería preciso invocar una teoría de los derechos humanos: "el aglutinante social que mantiene unida a la sociedad liberal ideal descrita en el cap. anterior consiste en poco más que el consenso en cuanto a que lo 
derecho iniciada a finales de la Edad Media ${ }^{41}$, y se abre el campo a los modernos conflictos de derechos, que alimentan, entre otros, el ya mencionado debate entre los pro-life y los pro-choice. Lo habitual en debates como ésos es que los partidarios de una y otra postura absoluticen sus respectivos derechos ${ }^{42}$, emprendiendo entonces una batalla dialéctica cuyo único fin es mostrar que la vida es superior a la libertad, o que la libertad es superior a la vida. Sin embargo, hay algo de insatisfactorio en esas controversias, en las que cada uno se parapeta detrás de su derecho, sin llegar jamás a un punto de encuentro.

esencial de la organización social estriba en dar a todos la posibilidad de crearse a sí mismos según sus capacidades, y que esa meta requiere, aparte de paz y prosperidad 'libertades burguesas' clásicas. Esa convicción no se basaría en concepción alguna acerca de determinados fines humanos universalmente compartidos, los derechos humanos, naturaleza de la racionalidad, el bien del hombre, $o$ acerca de alguna otra cosa. Sería una convicción basada en nada más profundo que los hechos históricos que sugieren que sin la protección de algo como las instituciones de la sociedad liberal burguesa, las personas serian menos capaces de resolver su salvación privada, de crear su autoimagen privada, de volver a urdir sus tejidos de creencia y de deseo a la luz de otras personas o libros nuevos cualesquiera con que se haya llegado a tropezar. En una sociedad ideal así, la discusión de los asuntos públicos girará en torno a: 1) cómo equilibrar las necesidades de paz, de bienestar y de libertad cuando las condiciones exigen que una de esas metas sea sacrificada en favor de las otras, y 2) cómo igualar las oportunidades de creación de si mismo y dejar entonces que las personas aprovechen o desaprovechen, por propia decisión, esas oportunidades": R. RORTY: Contingencia, ironia y solidaridad, Barcelona: Paidós 1991, pp. 102-103.

41 Cfr. M. VILLEY: La formation de la pensée juridique moderne, Paris: Dalloy 1975. Partiendo de la diferenciación entre derecho objetivo -ius- y derecho subjetivo -facultas-, unidos en la concepción tradicional del derecho, Villey mostraba a Ockham como el consumador de la ruptura. Posteriormente, Tuck, en su libro Natural Rights Theories: Their origin and their development, (Cambridge University Press 1979) criticaría algunos aspectos del libro de Villey, pero básicamente exploraria la historia de "derecho subjetivo", indagando los presupuestos conceptuales de un fragmento de la Summa Silvestrina.

42 Olvidando mientras tanto que, en el planteamiento kantiano, la expresión "derecho humano" se refiere a los derechos de la humanidad en la persona del otro. Cfr. S. KONIG: Zur Begründung der Menschenrechte..., p. 248. 
$\mathrm{Y}$ es que si tenemos presente que el punto de encuentro entre los seres racionales es precisamente la justicia, y que el objeto de la justicia es lo justo o el derecho, nos encontramos que, siguiendo esta línea de pensamiento libertaria, habríamos llegado a una concepción del derecho desligada de la justicia. Desde esta perspectiva salta a la vista el abismo existente no ya entre las modernas declaraciones de derechos humanos y la doctrina clásica del derecho natural, sino también el existente entre los derechos humanos tal y como los entiende Kant y como los entiende un liberalismo no matizado por la reflexión trascendental. Lo que tenemos entonces no es simplemente dos ideas del derecho, sino, más radicalmente, dos conceptos de hombre tan alejados entre sí como lo pudieran estar el de Calicles y el de Sócrates en el Gorgias platónico.

Así, en unos términos bastante parecidos a los de Calicles, el liberalismo extremo tiene una respuesta propia a la pregunta por la fundamentación de los derechos humanos: lo que sirva al proyecto subjetivo de vida. Naturalmente, si lleváramos esto hasta el final cuestionaríamos por su base la vida social ${ }^{43}$. Por ello, el liberalismo extremo -ahora ya más cercano a Protágoras- encuentra un camino . intermedio a la hora de formular los derechos humanos: la convención ${ }^{44}$. Efectivamente, a partir de lo que hemos dicho, es claro

43 De lo cual es bien consciente el mismo Rorty. Por eso propone como solución un compromiso pragmático entre la postura representada por los liberales más atentos a la creación de si mismos, y los liberales más preocupados por la creación de una sociedad más justa y más libre. Su solución pragmática se basa en la aceptación de la contingencia de nuestras convicciones más profundas - por tanto en la adopción de una postura postmetafísica- y en la férrea separación de lo privado y de lo público.

44 "Nuestra insistencia en la contingencia, y nuestra consiguiente oposición a ideas tales como 'esencia', 'naturaleza' y 'fundamento', hacen que nos sea imposible retener la noción de que determinadas acciones y determinadas actitudes son naturalmente 'inhumanas'. Pues aquella insistencia implica que lo que se considere un ser humano como es debido, es algo relativo a la circunstancia histórica, algo que depende de un acuerdo transitorio acerca de qué actitudes son normales y qué prácticas son justas o injustas. No obstante, en épocas como la de Auschwitz, en las que en la historia se produce un cataclismo, y las instituciones y las normas de 
que si prescindimos de la fundamentación trascendental kantiana o de la fundamentación trascendente, el único "fundamento" posible para determinar los derechos es la convención.

En este punto conviene precisar que a la formulación convencional, en cuanto tal, no habría, en principio, nada que objetar, siempre y cuando responda a un deseo o sentir natural. Después de todo, el impulso decisivo para la elaboración de una convención sobre estas cuestiones es siempre, de hecho, una convicción natural, a saber: que no toda justicia es convencional. Por eso, en la medida en que la convención misma responde a un sentir o deseo natural, la plasmación de esa convención en un código no distará mucho en la práctica de los principios elementales del derecho natural. Por lo demás, es claro que, en otro orden de cosas, la convención misma es necesaria para dotar de eficacia politica concreta a aquellos principios naturales.

Lo problemático no es, pues, la convención en sí misma sino, de una parte, el que ésta, contradiciendo su propio origen natural, se constituya en criterio último de fundamentación y, de otra, el que, en la práctica, en lugar de responder a la voluntad natural, responda a intereses particulares o ideológicos. Esto es lo que ocurre cuando los derechos humanos se esgrimen como un arma retórica para defender intereses occidentales, en los que, a todas luces, se falta a la justicia. Al ser la justicia una virtud para la cual todo hombre tiene aptitud natural -por mucho que en ocasiones dicha capacidad se encuentre debilitada o experimente corrupciones-, cualquier hombre está en principio capacitado para reconocer las injusticias que, en ocasiones, se cometen apelando a los derechos humanos. (Paradójicamente, pues,

conducta tradicionales se desploman, deseamos algo que se encuentre más allá de la historia y de las instituciones. ¿Qué otra cosa puede ser, si no la solidadridad humana, nuestro reconocimiento de una humanidad que nos es común? En este libro me he esforzado por hacer ver que debemos intentar no aspirar a algo que se encuentre más allá de la historia y de las instituciones": R. RORTY: Contingencia, ironia y solidaridad..., pp. 207-208. 
lo que se demuestra más fuerte es aquel sentido natural de justicia que a la Ilustración inspiraba poca confianza).

En esta línea no debería extrañar que hoy se encuentre tan sujeto a crítica, sobre todo en el seno de la cultura árabe, para quienes la fe en el Corán salvaguarda de una manera más adecuada la dignidad del hombre ${ }^{45}$. Ocurre, en efecto, que en círculos árabes las declaraciones de los derechos humanos son consideradas productos de la civilización occidental que carecen de validez para otras culturas. En ello hay parte de verdad. $Y$ es que el lenguaje de los derechos humanos responde a una tradición concreta, inequívocamente occidental.

Sin embargo, tomar conciencia del origen europeo de este lenguaje no conduce necesariamente a relativizar las intuiciones morales mediadas por él. En este punto es oportuno distinguir, con Spaemann, entre génesis y validez. La génesis de un cuadro no justifica su valor. Para apreciar su belleza no es esencial conocer los detalles de su composición. Análogamente: la génesis occidental de las declaraciones de derechos humanos, con todas sus limitaciones, que se han ido señalando, no dice nada en contra de la verdad de algunas de las intuiciones que ese lenguaje pugna por expresar. Así, en la medida en que los derechos humanos se presentan a sí mismos como concreciones del respeto debido a toda persona humana, sí puede admitirse que su positivación constituya un punto de referencia que invite a promover el respeto a la dignidad humana en todos los puntos del planeta. Después de todo, la palabra escrita tiene al menos el efecto de un recordatorio, siempre y cuando haya algo que recordar, es decir, siempre que haya algo natural.

45 Cfr. U. STEINBACH: "Der schöne Schein ist längst verblaß. Vom Sinn eines Menschenrechtsdialogs mit Teheran", en Frankfurter Allgemeine, Dienstag 28 Marz, n. 74, pág. 11. 
5. La síntesis práctica del derecho natural clásico y las declaraciones modernas de derechos humanos

Esta última alusión a la naturaleza no carece de importancia; por muchas razones. Ya anteriormente hemos apuntado que de nuestro modo de comprender la naturaleza depende en gran medida nuestro modo de comprender la libertad y la dignidad: Si la naturaleza es vista como pura facticidad, los fines que ella incoa carecen de sentido, están vacios de racionalidad. $\mathrm{Si}$, por el contrario, la naturaleza no es pura facticidad, si está penetrada de racionalidad, los fines que incoa son dignos de consideración y pueden resultar relevantes para nuestra acción. En esta línea, la naturaleza sensible no es pensada como una instancia totalmente ajena a la racionalidad y la libertad. Por el contrario, si la misma virtud puede describirse como un diálogo entre naturaleza y razón es porque la naturaleza atiende a razones, y, en cierto sentido puede "reconocer" que su aspiración más profunda se cumple cuando la razón práctica introduce orden en: sus bienes propios, promoviendo así la virtud moral ${ }^{46}$.

La importancia de esto último para el tema que nos ocupa se puede calibrar cuando reparamos en la relación existente entre virtud y dignidad moral. Por aqui, en efecto, entrevemos ya una pista valiosa para elaborar una sintesis práctica entre la doctrina clásica del derecho natural y los distintos derechos humanos. Nótese que no hablo aquí de la teoría de los derechos humanos, sino de los distintos derechos humanos, tal y como se encuentran recogidos en cualquier código. Y:es que, considerando los derechos uno por uno, la cuestión decisiva no es tanto la de elaborar una jerarquía abstracta de derechos, como la de usar correctamente cada derecho en cada caso

46 "Uno puede estar sometido a la ley como un forzado a sus cadenas. Y en este sentido no son los hombres justos y virtuosos, sino sólo los malos los que están sujetos a la ley. Porque lo forzoso y violento es contrario a la voluntad; mas la voluntad de los buenos está en armonía con la ley, mientras que la de los malos discrepa de ella. Por ende, en este sentido, los buenos no están sujetos a la ley, sino sólo los malos": TOMÁs DE AQUINo: Summa Theologiae, I-I", qe. 96, a. 5, c. Cfir. Summa Theologiae, I- $\Pi^{\text {ae }}$, q. 93, a. 6. 
concreto. Ahora bien: para ello es indispensable el derecho natural tal y como lo entendian los clásicos: como una mentalidad forjada en la práctica de la virtud moral, a la que va inseparablemente unida la prudencia: un saber práctico por el cual sabemos hacer uso de los distintos bienes, ordenándolos a la integridad del bien humano.

Cuando en este contexto hablo de una sintesis práctica de la doctrina del derecho natural con los distintos derechos humanos, por tanto, tomo los distintos derechos como bienes dentro de los cuales debemos introducir orden, de lo cual se ocupa la razón práctica perfeccionada por la prudencia. $\mathrm{Y}$ es precisamente esta sintesis práctica la que, según lo entiendo, se encuentra ausente del planteamiento kantiano, y, a causa de ello queda un poco desasistido en la práctica. Desde él puede sin duda defenderse universalmente la dignidad humana. Se puede hablar una y mil veces de que el hombre es fin en sí mismo, y argumentar a partir de ahí la existencia de derechos humanos inalienables. Con todo, esta insistencia teórica no termina de ofrecernos un criterio práctico de actuación, pues éste sólo puede obtenerse por la familiaridad del agente con la virtud moral.

De este modo, si el lenguaje de los derechos humanos y su fundamentación en la idea de dignidad es una aportación de la filosofia moderna, la aportación clásica se cifra más bien en la consideración del derecho como un instrumento que requiere ser usado con buen criterio: con el buen criterio que proporciona únicamente la prudencia, y con ella, la virtud moral. En estas palabras ya se advierte que la sintesis entre los dos planteamientos es una síntesis práctica. ¿Qué hay de su complementariedad teórica?

A este respecto conviene recordar lo que apuntábamos al comienzo: que ambas doctrinas no admiten una superposición simple, porque, como hemos visto, parten de distintos conceptos del derecho. Asi, mientras que la doctrina clásica del derecho natural se basa en una concepción relacional del derecho, subrayando de este modo la naturaleza social del hombre, la teoria modema de los derechos humanos parte de una idea del derecho como posesión, subrayando en 
mayor medida la centralidad del sujeto humano. Por eso, a la hora de justificar sus propuestas, :el derecho natural clásico apela más a la naturaleza; mientras que las teorías modernas de los derechos humanos apelan a la dignidad humana.

Que dignidad y naturaleza no se excluyen es un asunto claro para quien se mueva en las coordenadas de la metafisica clásica. No lo es tanto para quien se mueva en el marco de la filosofia moderna. Por eso, si para el primero puede resultar dificil ensayar una sintesis entre la doctrina clásica del derecho natural y los distintos derechos humanos, para el segundo tal sintesis resulta sencillamente imposible. Efectivamente, dicha síntesis; necesariamente práctica, sólo resulta posible, a mi juicio, cuando descubrimos, en el nivel ontológico, la conexión existente entre dignidad y naturaleza y, en el nivel práctico, la necesidad de completar la formulación de los derechos con su correcta aplicación, para lo cual es indispensable contextualizar el derecho en el marco de una teoría de la virtud.

Al margen de dicha sintesis práctica, en el plano teórico eś posible hablar, a lo sumo, de una complementariedad entre ambas doctrinas. Para ello, es necesario advertir. que cada una de ellas goza de un diverso estatuto épistemológico. Así, mientràs que la doctrina clásica del derecho natural es una doctrina primordialmente práctica -se enmarca en la doctrina de la justicia-, la doctrina moderna de : los derechos naturales, con su apelación expresa a la dignidad humana, se sitúa en un ṕlano trascendental, o, si queremos, ontológico: Este diverso estatuto epistemológico determina la aportación específica de cada teoría, sencillamente porque es distinto el objeto de:la metafisica y el objeto de la filosofia práctica. Ahora bien: si la fundamentación del derecho es ontológica o: trascendental, el derecho mismo es una disciplina práctica. En este sentido, la teoria de los derechos humanos, apelando a la dignidad, responde al primero de los objetivos; en cambio, el derecho natural clásico se encuentra en mejores condiciones para afrontar los problemas prácticos relativios a la aplicación prudente - y finalmente justa - de aquellos mismos derechos. 
Copyright of Tópicos. Revista de Filosofía is the property of Universidad Panamericana and its content may not be copied or emailed to multiple sites or posted to a listserv without the copyright holder's express written permission. However, users may print, download, or email articles for individual use. 